\title{
Public Healthcare Expenditure and Health Sector Performance in Nigeria: Implications for Sustainable Economic Development
}

\author{
${ }^{1}$ Olarinde Muftaudeen O, A. A Bello ${ }^{2}$ \\ ${ }^{1,2}$ Department Of Economics, Usmanu Danfodiyo University, Sokoto
}

\begin{abstract}
This paper uses the concept of co-integration in an empirical analysis of the long-run relationship of Nigeria's public healthcare expenditure, institutions and health sector performance outcome. The analysis employs the use of annual data for the sample period from 1970 to 2011. The purpose of this study is to investigate and explain the impact of government healthcare expenditure and the quality of institutions on the sector performance outcome as well as provide a more in-depth analysis of the important of institutions in determining a sustainable positive health sector outcome with its multiplier effects on development. The autoregressive distributed lag (ARDL) and VECM granger non-causality techniques were used for estimating the long-run and short run coefficients of the health sector model as well as to confirm direction of causality between the variables. The empirical results from ARDL bound testing approach provide strong evidence of the existence of a long-run and short-run stable relationship among the variables included in both models. In addition, both models estimated in this paper offer empirical results, which support the hypothesis that good institutions are germane to positive health sector outcome, and that causality runs from all the variables in the model to infant mortality rate. This is an important finding for the achievement of healthy human capital necessary for a sustainable economic development in Nigeria.
\end{abstract}

JEL Classification H72; HIIO; H51; I-18; O-15

Key Words: Infant mortality, Institutions, Granger causality, Health, Economic development

\section{Introduction}

Health is one of the most important factors that determine the quality of human capital, a necessary factor for economic growth. In line with the above, a consensus of opinion have been formed among researchers recognizing health as a public good, the demand and supply of which cannot be left at the mercy of invisible hands or profit maximizing individual as well as on considerations of utility maximizing conduct alone. Hence, the need for the government to play a major role in delivering good and qualitative healthcare services that is accessible and affordable for the teeming population.

The recognition of the importance of the above led the World Health Organisation (WHO) to propose at the 2010 World Health Assembly, issues that will address financing of health, which will ensure qualitative and affordable healthcare services (Ataguba and Akazili, 2010). The pattern of health financing is therefore closely and indivisibly linked to the quality of health outcomes (health status), capable of achieving the long $* * *$ term goal of enhancing nation's economic development (Riman, 2012).

Alluding to the above fact and as an evidence of its commitment towards the restructuring of the health sector in its fiscal operation, the Nigeria government has taken up the responsibility of providing good healthcare facility for its citizens by improving on the amount of its expenditure on health. Available data indicated that on the average about $2.1 \%$ to $5.8 \%$ of total government expenditure were expended on health within 2000 and 2007 (Mordi, 2010). The belief is that this would improve the health of the citizenry that can translate into healthy human capital base with its multiplier effects on economic growth and development.

Despite this improvement in health spending, the country still lagged behind compared to other countries in the continent. Statistics have shown that the country's public expenditure on health as a percentage of GDP is 4.1 percent against 4.6 percent African average and over 6.3 percent in developed countries. With these efforts, Nigeria overall health status or sector performance outcomes have not been so encouraging. According to Yaqub et al. (2010), the country overall health performance was ranked 187th among the 191 Member States by the World Health Organisation (WHO) in 2000. The table (1) gives a more detail picture of the health sector outcome in the country. 
Table I: Showing the State of Health Outcome, Quality of Institutions and level of Income in Nigeria from $2006-2011$

\begin{tabular}{|c|c|c|c|c|c|c|c|c|}
\hline Year & $\begin{array}{l}\text { Pop. } \\
\text { Growth } \\
\text { Rate }\end{array}$ & $\begin{array}{l}\text { Malnutrition ( } \% \text { of } \\
\text { Child ren Under } \\
\text { Syrs) in weight }\end{array}$ & $\begin{array}{l}\text { HIV Prevalence } \\
\text { Rate }(0 \% \text { of } \\
\text { Population ages } \\
15-49 \mathrm{yr})\end{array}$ & $\begin{array}{l}\text { Infant Mortality rate } \\
\text { (per 1,000 live birth) }\end{array}$ & $\begin{array}{l}\text { Life } \\
\text { Expectancy }\end{array}$ & $\begin{array}{l}\text { Access to } \\
\text { Improve } \\
\text { Sanitation as } 0 \% \\
\text { of total } \\
\text { Population }\end{array}$ & $\begin{array}{l}\text { Rule of } \\
\text { Law* }\end{array}$ & GDP pc \\
\hline 2006 & 2.48 & & 5.3 & 93.6 & 49.2 & 32.3 & -108 & 1,0147 \\
\hline 2007 & 2.49 & 2.57 & 5.1 & 90.7 & 49.8 & 32.0 & -1.07 & 1.1273 \\
\hline 2008 & 2.49 & 26.7 & 5.0 & 87.8 & 50.3 & 31.7 & -1.06 & 1389.7 \\
\hline 2009 & 2.51 & & 4.9 & 85.1 & 50.8 & 31.3 & -1.16 & $1,085.0$ \\
\hline 2010 & 2.52 & & 4.8 & 82.6 & 51.3 & 31.0 & -1.17 & $1,431.6$ \\
\hline 2011 & 2.8 & 24.4 & 4,7 & 80.1 & 51.7 & 30.6 & -1.21 & $1,486.0$ \\
\hline SSA & 2.7 & $20.8^{44}$ & 3.4 & 65.8 & 55.9 & 30.5 & - & 1.415 .0 \\
\hline
\end{tabular}

Source: UNECA (2012); World Development Indicators (2013); Kauffman et al.(2013)

Note: * figures range between -2.50 to 2.50 .

** Figures are for Sub-Saharan Africa in 2010

Although Infant mortality fell from 140 in the 1970 s to 87.8 and 80.4 per 1000 birth in 2008 and 2011 respectively as shown in table (1), the rate is still higher than the regional average (SSA) of 70.2 and 65.8 for the years under consideration and 57.3 in 2010 throughout developing countries. Life expectancy is only 49.8 years compared with 53.5 years for Sub Saharan Africa, 65.4 years for developing countries in 2007, while in 2011, the country only managed to achieved marginal improvement with value of 51.7 (AfDB, 2011; UNECA, 2012; World Bank 2013).

An improvement in health status of the citizenry is an important prerequisite for achieving human capital development in every economy with its multiplier effect in skillful, efficient and productive investment in human capital that will translate into economic development. A glance at the overall Human development index of the country portrays a disappointing picture of its quality of human capital. The country ranked $153^{\text {rd }}$ position among 187 countries on the HDI ranking in 2012 with HDI value of 0.47 . Although the country experienced an improvement on the HDI ranking compared to its rank of $155^{\text {th }}$ in 2011 , still the country cannot make the first ten countries with the highest HDI value in Africa falling behind Kenya Cameroon and Ghana (U N D P 2013). Iincrease in budgetary allocation spent on the provision of social services is highly advantageous in a developing country like Nigeria, this by itself is not sufficient to guarantee enhancement in service delivery. The graphs of Government expenditure on healthcare and health status of some countries in the region below lend support to the above assertion.

Fig 1: Chart Showing Government Health Expenditure and Life Expectancy Rate of Some Selected Countries in Sub Sharan Africa (2002-2011)

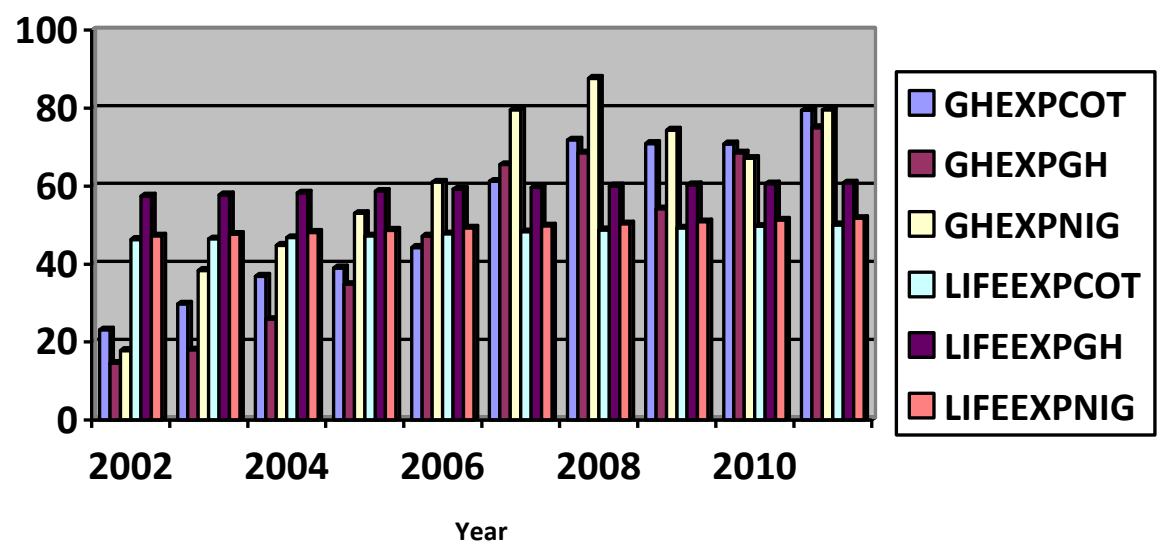

Note: GHEEXPCOT $=$ Cotedoivoire Government Expenditure on Health LIFEEXPCOT $=$ Cote doivoire Life Expectancy Rate GHEEXPNIG =Nigeria Government Expenditure on Health GHEEXPGH $=$ Ghana Government Expenditure on Health LIFEEXPNIG $=$ Nigeria Life Expectancy Rate in

LIFEEXPGH= Ghana Life Expectancy Rate in Cote doivoire

Source: World Bank Data, 2013 
The above graph compares the level of government financial commitment on health expenditure and outcome in term of life expectancy rate of some countries in sub Saharan African (Ghana and Cote devoir) that are belief to have achieved certain level of development with Nigeria. The figure reveals that between $2006-$ 2011 excluding 2010, the country's total expenditure on health remained the highest among the three countries, but in term of outcome the country has continued to be at per with cote devoire that has lowest value in term of government health expenditure. A further glance at table (1) reveals a persistence deterioration of the quality of institutions between 2008 to date, which may serve as an explanation to poor performance outcome of the sector. Institutions are expected to facilitate ideas and innovation, define property rights and encourage strict enforcement of contracts, lower transaction cost and correct government failure, reducing uncertainty as well as fostering efficiency hence enhance strong economic performance (Ajayi, 2002; North, 1991). The absence of which has impacted negatively on the economic development of the country resulting into unsustainable pattern of growth in income per capital, worsening standard of living in term of deteriorating level of access to improve sanitation, high percentage level of malnutrition among children compared to Sub-Saharan African average, as well as poor HDI ranking (see table 1). All culminated into an upward rising government health budgetary allocation that is not measurable with outcome as shown below.

Fig.2: Trend of Government health Expenditure, Infant Mortality Rate and Under Five Mortality Per 1,000 Live Birth in Nigeria (1970-2011)

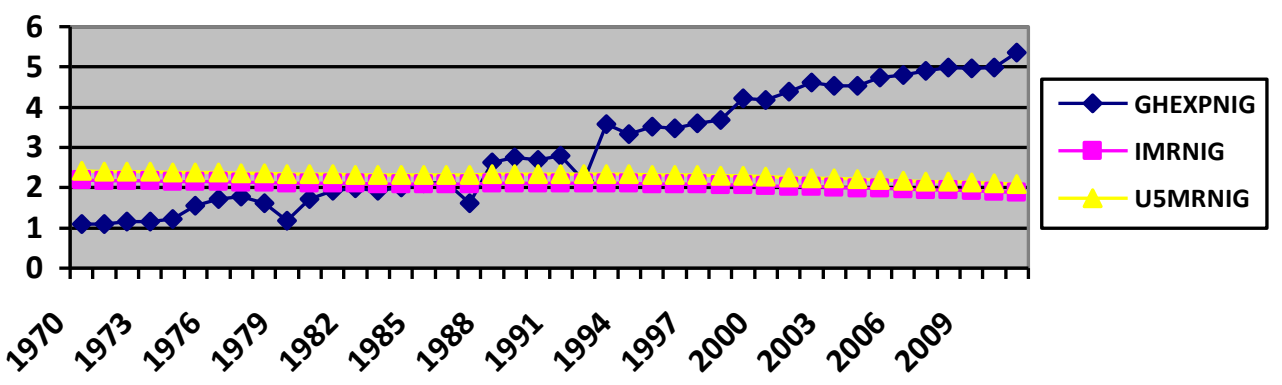

Note: GHEXPING = Government Expenditure on Health

IMRNG = Imfanf Mortality Rate

U5MRNG =Under-five Mortality

Source: world Bank Data, 2013

Although Infant mortality rate (IMR), the probability of dying before age one and Under-five (child) mortality (U5MR), the probability of dying between birth and age five years expressed per 1000 live births which have been a common indicator for children's wellbeing experienced a decline from 2001 till date, the trend remain unacceptable compare to exploding trend of health sector expenditure.

The above scenario tends to call for re-examination of the establish relationship between healthcare expenditure and outcomes in Nigeria. It has however been confirmed that the differences in the level of development among countries of the world is not just due to differences in natural endowment and macroeconomic policies but to some extent depends on institutional environment prevailing in an economy. There are many empirical works on health expenditure and outcomes nexus, a handful of them uses cross country data with assumption of homogeneity (Odusola, (1998); Gupta et al. (1999), and Kaufman et al. (2004), Anyawu et al., 2007, Bakare et al. 2011; Yaqub,). Most of these studies did not focus on Nigeria. Those on Nigeria only concentrated on the effect of public expenditure on health outcome with the exceptions of yaqub ( ) that tries to provide a link between Healthcare expenditure, health outcome and corruption. This is not without its shortcoming by using variables that are based on perception as well as inability to determine the chain of causality. This notwithstanding, they all suffered from omitted variables bias as well as neglecting the role of institution in relation to rule of law and level of trust in the determination of health outcomes in Nigeria. It is against this background that the paper sought to fill the vacuum by investigating the impact of government health expenditure on the level of economic development in relation to health indicator putting into consideration the prevailing country's institutional quality, examining direction of causality, the effectiveness of various health programme and justification for investing public funds.

Subsequent to section 1, Section 2, is a review of the existing literature. Section 3 is an explanation of the model and estimation procedure. Section 4 analyses the results and finally, Section 5 however concludes the paper with the policy implications. 


\section{Review of Theoretical and Empirical Work}

\section{1: Theoretical Framework}

Theoretically, linking healthcare spending to health outcomes have generated lots of debate between the medical scientist and health economist culminating into difference schools of thought with diverse opinion. First among these is the Mosley -chen model of mortality developed by Mosley and Chen (1984) The model attempt to bridge the gap between social science approach and medical approach, thus the model suggested combining social science and medical science approaches to study child survival in developing countries. The model is built on a transmission mechanism as shown below.

\section{Socio economic status $\rightarrow$ Proximate Determinants $\rightarrow$ Risk of Diseases $\rightarrow$ Mortality outcomes}

Their argument follows that the social economic status influences the proximate determinants of health and risk of diseases, which in turn directly influence health and mortality outcome. The proximate determinant has to do with level of hygiene and sanitation of the environment in which an individual finds his/her self. Based on their analogy, the model implies that health outcome (child mortality rate) should not be treated as single cause and that it is necessary to specify order of causality as well as study the possible interaction across the socio-economic determinants.

Looking at the linkage between healthcare expenditure and health outcome from the economic point of view is the economic growth oriented theory by Filmar and Pritchett (1999). In their view, macroeconomic condition explains most of the differences in child and infant mortality rate. They conclude that public healthcare expenditure does not have any significant positive impact on health sector performance. Further studies in the establishment of the link between public healthcare expenditure and health outcome have shown that public expenditure on health does have an impact on health outcomes. For instance, Gupta et al. (2001) used cross-country data to show that the relationship between public spending on health and health status is significant and stronger for the poor people and argued that public health policy matters more to the poor. Collaborating the above school of thought is an empirical study carried out by Hummer et al (2003) which shows evidence that support the importance of public health intervention and refutes the view that economic growth is the main determinants of child health outcome.

Another strand of thought is the Rajkumar and Swaroop (2008) theory that provides an explanation on the reason behind the mixed evidence found in the relationship between public expenditure on health and health sector performance. They concluded that it is not simply true that public health expenditure per se does not have any significant positive impact but government efforts and bureaucracy quality determined weather public spending could have a significant impact on the final health outcome.

\section{2: Review of Empirical Literature}

Empirical literature on the relationship between public healthcare expenditure and health sector performance are limited, especially in relation to Nigeria. Of importance is the fact that, papers that summarize the discussion on the effects of health expenditures as well as chain of causality often advocate conflicting views. Some studies find a positive relationship between public healthcare expenditure and health sector performance (e.g. Anand and Ravallion, 1993; Patricio, 2008; Imoughele et al. 2013; Olaniyan, et al 2013), while others found no relationship between the public health expenditures and the health sector performance (Filmer and Pritchett, 1997; Kim and Moody, 1992; Musgrove, 1996). Yet several other empirical studies have shown that quality of institutions is an important factor in explaining health sector performance outcomes, but is not alone determinative (ARAH, 2003; Maureen, 2006; Anyawu et al, 2007; Bingjie Hu, 2010).

Investigating the relationship between health expenditures and health outcomes by Baldacci (2004) using a panel data set for one hundred and twenty developing countries form 1975-2000. He discovered that spending on health within a period affects growth within the same period while lagged health expenditures appear to have no affect on growth. He inferred from this result that the direct effect of health expenditure on growth is a flow and not a stock effect. Other studies such Greiner (2005), Strauss and Martins (2005) and Agenor (2007), all conducted researches in respect of other countries and affirmed that health expenditure is positively related to economic growth. What differ from one country to another is the extent and magnitude of its contributions.

In a related studies, Anyawu et al (2007) examining the linkage between African countries' (group into different geographical locations) per capita total as well as government health expenditures to infant mortality and under-five mortality between 1999 and 2004 albeit with mixed results. Their result reveals that Health expenditures have a statistically significant effect on infant mortality and under-five mortality and that total health expenditures are certainly important for African countries depending on each region peculiarities. They conclude that both infant and under-five mortality are positively and significantly associated with Sub-Saharan Africa while reverse is true for North Africa. 
Bidani and Ravallion (1997) in their study applied a cross-section regression analysis, disaggregating health outcomes indicator as an additional explanatory variable. Their results suggested that per capita health spending was positively related to the life expectancy of the poor, but it had no significant link to the life expectancy of the rich. As a robustness check, a similar result was found when a different poverty cut off point was used. From the results, it is evident that public health spending had a larger impact on life expectancy and infant for those living on less than $\$ 1$ a day as compared to the results focused on poor people defined using the $\$ 2$ a day as poverty line.

In his own view, Patricio (2008), looking at health outcomes in Russia operating through institutional efficiency, his results suggested that health outcomes in Russia are similar to countries, which spend $30-40 \%$, less on health which suggests considerable inefficiency in the Russian health system. A second implication of the findings of this report is that in order to improve health outcomes, as well as needs for additional resources for healthcare, which should be accompanied by reforms to improve efficiency and effectiveness of healthcare organization and delivery.

Chaabouni and Abednnadher (2010) examined the determinants of health expenditures in Tunisia during the period 1961-2008, in an attempt investigated the chain of causality using the Autoregressive Distributed Lag (ARDL) approach by Pesaran et al. (2001). On the one hand the results of the bounds test showed that there is a stable long-run relationship between per capita health expenditure, GDP, population ageing and medical density among others. On the other hand, results of the causality test showed that there is a bi-directional causal flow from health expenditures to income, both in the short and in the long run. They recommended that policies aiming at encouraging health expenses are required to build up a healthier and productive society to support the Tunisian's economic growth and development.

A few studies conducted in Nigeria that has the largest percentage of the African population with relatively high rate of poverty, on healthcare expenditure and outcomes remained inconclusive. Rahman, Bassey and Edu (2011) examined healthcare expenditure in Nigeria; as to whether the level of government spending for the period between 1980 and 2003 has any impact on economic development of the nation. Their finding is that life expectancy as well as literacy rate were negatively correlated with healthcare expenditure both in the short and long run, and that income elasticity of healthcare expenditure was below unit both in the short and long run.. Their recommendation is that government needs to increase funding of health sector and reduce the inequality in the budgeting distribution of health expenditure in order to improve the health status of Nigerians. The above view was shared by Olayinka et al. (2013), drawing from their result in a paper on health expenditure and health status in northern and southern Nigeria. They concluded that in the light of low income of majority of the people, especially in the north, stewardship role of the government has to increase in terms of funding healthcare, if the health status of the populace is to improve. However they are apt to note that without government being directly involved in the provision of healthcare services, attempt should be made to subsidise the private sector and increase regulatory capacities (institutional quality) to improve the overall availability and accessibility of health services to the citizenry.

Confirming the above, Imoughele, (2013) empirically examines the determinants of public health expenditure in Nigeria. Using the error correction techniques and time series data from 1986 to 2010, the results show that demand for health in Nigeria is price Inelastic. Further in their studies, they concluded that total population of children that falls within the age of 14 Years and below and health expenditure share in gross domestic product (proxy for government developmental policy on health) are the major determinants of health expenditure in Nigeria. To this end, the study recommended that to make government health expenditure to have a robust effect on Nigerians health status and meet WHO recommended budgetary allocation to the sector, Government Budgetary allocation to health sector should be increased to the prescribe of $15 \%$ of its annual budgetary allocation to the health sector.

In a contrary opinion, Filmer and Pritchett (1997) Kim and Moody, 1992, Musgrove 1996) Filmer and Pritchett find no evidence that total spending on health has any impact on child mortality. Filmer and Pritchett (1997) empirical evidence support the hypothesis that public spending on health is not the major determinant of child mortality outcomes rather, the level of poverty, income inequality, female education, and other socio cultural factors explain practically major differences in child mortality across countries. Based on the above, they recommended institutions of policies that can serve as a catalyst for growth in income, reduce poverty and income inequality, and increase female education.

It must be asserted that the analysis of the impact of public health expenditure on the health sectors outcomes must necessarily involve its mechanism (like quality of institutions), the stimulation of which can improve a country level of growth. Empirical results on the linkage between healthcare expenditure and health outcome reveals a general consensus among researchers that qualitative institutions are germane to positive health outcome.

Bingjie Hu (2010) looked at the empirical determinants of infant and child mortality in developing countries and how public policy may interact with these. Using panel data analysis covering 136 countries over 
1960-2005, as well as a broad variety of alternative indicators of governance. The result corroborates earlier findings that governance does play a role in enhancing the link between public spending and child health. Maureen (2006) further supports this when he concludes that good governance is important in ensuring effective healthcare delivery, and that returns to investments in health are low where governance issues are not addressed. The above conclusion is in line with earlier empirical works by Gupta et al. (1999), Kaufmann et al. (1999) and Kaufman et al. (2004), alluding to the fact that governance indicators such as voice, accountability, rule of law political stability and violence among others have a strong direct negative impact on infant mortality while countries with high corruption have high child and infant mortality rates

Looking at how public health expenditure influences economic development of an economy through the availability of a qualitative human capital, Chete and Adeoye (2002), using Vector Auto regression analysis and ordinary Least Square to capture these influences. They conclude that there is an unanticipated positive impact of human capital on growth. This has been appreciated by various pass regimes in Nigerian since post independence era, through prodigious expansion of educational infrastructure across the country; but they are quick to point out that the real capital expenditure on education and health have been rather low.

Yaqub et al. (2010), investigating how the effectiveness of public health expenditure is affected by governance in Nigeria using two stage least square method. The result attained showed that public health expenditure has negative effect on infant mortality and under-5 mortalities when the governance indicators are included. They conclude that the achievement of the Millennium development goal of lowering infant mortality by two-thirds by 2015 ; reducing under- 5 mortality rate while raising life expectancy in Nigeria may be unachievable if the level of corruption is not reduced significantly. No wonder that Andrew (1995) asserts that the process of reform is not concerned only with defining priorities and policies, but with reforming and restructuring the institutions through which health policies are implemented.

\section{1: Sources of Data}

The authors intend to use times series data covering a period of $1970-2011$. The choice of this period is based on the fact that, the period marked the beginning of the era of pronounced institutional decay as well as health sector reforms in the country that has not to some extent, transformed into sustainable economic development. The data for this research work will be mainly secondary data obtained from CBN, The World Bank, and other relevant publications.

\subsection{Model Specification and Econometric Methodology}

Different estimation methods (Cross sectional analysis, Panel, and VAR etc.) have been used in carrying out an empirical analysis on the relationship between healthcare expenditure and health outcome, each with their associated limitations. For example, using cross-sectional analysis, one cannot convincingly establish that deterioration in governance is associated with deterioration in output'. Few have tried to use panel data as an estimation method, with its limitation of taking the simple levels of variables without instrumenting them.

Recently a relatively new techniques - the autoregressive distributed lag model. (ARDL) approach, developed by Pesaran and Shin (1999) and further developed by Pesaran et al, (2001) was introduced to allow for causality and dynamics as well as testing for both short run and long run relationship among the variables The ARDL technique is considered more appropriate compared to other traditional approach mentioned above. The approach can be implemented regardless of whether the variables are integrated of order (1) or (0) and can be applied to small finite samples. The study is based on the assumption that improved health status in term of reduction in infant mortality rate is driven by high public healthcare expenditure and good institutions in the country (Rajkumar and Swaroop, 2008). The basic form of the relationship between the variables drawn from theoretical framework can be expressed as:

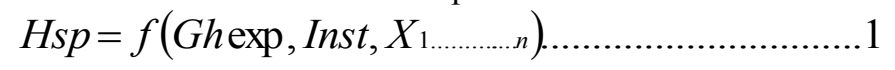

Where, (HSP) represents, Health Sector Performance, (Ghexp) represents Government healthcare expenditure, (Inst) represents institutional quality and $X_{1} \ldots \ldots . . n$ represent vector of other explanatory variables. The relationship can be expressed in an estimable equation as follows,

$$
H s p=\left(\beta_{0}+\beta_{1} G h \exp +\beta_{2} \text { Inst }+\beta_{3} L i t+\beta_{4} U p o p+\beta_{5} G d p p c+\varepsilon t\right) .
$$

The study employed a semi log-linear model specification, and is thus likely to give more definitive results. Thus equation (2) can be modified in a semi-log as follows.

$$
H s p=\left(\beta_{0}+\beta_{1} \text { Lngh exp }+\beta_{2} \text { LnInst }+\beta_{3} \text { Lnlit }+\beta_{4} U p o p+\beta_{5} \operatorname{Lngdppc}+\varepsilon t\right) .
$$

Where Lit represents literacy rate, Upop stands for Population of people living in the urban areas and Gdppc represents GDP per capita and $\beta 1 \ldots \ldots \ldots . . . . .5$, represent coefficients to be determined and $\mathrm{et}$ is the error term, all other variables remain as defined earlier. 


\section{3: Variables Measurement.}

HSP: Health Sector Performance Outcome is proxy by infant mortality rate (IMR) and under- five- mortality (U5MR). The Infant Mortality Rate (IMR) refers to the number of deaths per 1,000 live births while under-five mortality refers to number of death before the age of five years per 1,000 live- birth. It is generally agreed that IMR and U5MR reflect the level of mortality and the effectiveness of preventive care and the attention paid to maternal and child health. To capture the impact of government heath care expenditure on the performance outcome of the health sector, equation $2 \mathrm{~b}$ will be decomposed into two models having IMR and U5MR as dependent variables in each of the equation.

GHEXP: It represents Government healthcare expenditure .It is the amount of resources that flows into the health sector and it is expected to have negative relationship with the rate of infant mortality. This is captured by amount of government recurrent expenditure on healthcare.

INST: This refers to institutional quality in term of regulatory quality/rule of law, level of trust and contract enforcement right. They also include pattern of behavior, conduct determining the choice and execution of policies as well as formal and informal rules that are essential for economic performance outcome (Ajayi, 2002; Garba, 2012)

The robustness of the private sector in healthcare sector as well as effectiveness of public healthcare expenditure will be affected by factors such as low level of trust, poor regulation or an ineffective court system(Maureen, 2006; Yaqub, 2012, ). To capture this aspect of institutional quality we have used recently developed indices, the Contract Intensive Money (hereafter CIM) developed by Clague et al. $(1996,1999)$ as used by (Kiyotaki et al. 2005; Asekunowo,2010; Dantama, et al. 2013) for the measure of institutional quality.

CIM is calculated as

$$
C I M=f((m 2-c) / M 2) \cdots \cdots \cdots \cdots \cdots \ldots . . . e q u a t i i o n,(4)
$$

Where:

$M 2=$ a broad definition of the money supply

$C=$ currency held outside the banking system.

The benefit of using CIM as a proxy for level of trust and rule of law is that the data is available for many countries over a long period (from 1948 in some cases) as well as more objective because it avoids the problem of ordinality and perception inherent in other indices of institutional quality. Higher values of CIM (1) indicate a greater reliance on or preference for long-term contracts and high degree of trust in the economy while a lower value of CIM (0) indicates absolute lack of trust in the economy.

LIT: Literacy rate is an important determinant of the health status of infants and children, as well as the population in general (see Baldacci et al., 2004; World Bank, 1993; Schulz, 1993) proxy by total government expenditure on education. Literacy rate is positively associated with infants' health and consequently reduces infant mortality rate. This is because educated parents are more likely to be aware of nutrition and their children's health. It has been one of the most frequent explanatory variables in the literature (Anyawu et al. 2007)

GDPPC: Gross domestic product per capita is used as a proxy for level of poverty in the country. It is expected that poverty level determined the level of accessibility and affordability of healthcare facility as well as level of sanitation and nutrition by an household, hence ceteris paribus the higher the income of an household the lower the infant mortality rate.(Yaqub,2012; Anyawu et al.2007 )

Urban Population: This is captured by the growth rate in percentages of the total number of people living in the urban centre. It has been reveal that geographical location affects health status of an individual. It is expected that mortality rate among the urban dwellers will be lower compared to rural low - income household.

\subsection{Estimation Procedure}

This section outlines the application of ARDL techniques for co integration developed by Pesaran et al. (2001) to establish the long run relationship among health sector performance outcome, institutions, healthcare expenditure and other explanatory variables. Econometric theory suggests that if the variables are co integrated, there will be at least one linear combination of variables in the model. One implication is that most of the time, series data are non-stationary in nature, and the application of OLS techniques will result in spurious outcomes. This data requires that before the application of ordinary least squares (OLS) to estimate the relationship, it is necessary to establish the order of their integration: $\mathrm{I}(0)$ or I(1). Although bounds test is built on the probability that the variables are either integrated of order zero or one, the investigation of the unit roots properties using the ARDL techniques still becomes paramount to ensure that none of the variables is integrated of order two. 
Therefore, the times series properties of the variables used in the model were investigated to confirm their order of integration in order to avoid spurious regression using Augmented Dicky F, and Philip P.( )

After testing the non-stationary properties of the data, the study applied ARDL model techniques to establish the long run relationships between the variables in the model. In the first step of the ARDL analysis, we test the presence of long run relationships. General to specific modelling approach has been used. The number of lags of first differenced variables so selected is based on Akaike Information Criterion (AIC). Initially we set 3 lags and by using the general to specific methodology, we delete the insignificant variables from the model when justified by AIC and adjusted $\mathrm{R}^{2}$ moving in the right direction. Second, the long run relationship was estimated, followed by the short run coefficients thus using the error correction representation of the ARDL specification with a view to establishing the speed of adjustment to equilibrium using equation 5 through 9. The ARDL specification of equation 3 decomposed into model 1 and 2 can be stated as follows:

Model 1

$\Delta(I M R)_{t}=\beta_{0}+\eta_{1} I M R \phi_{t-1}+\eta_{2} \ln G \exp _{\mathrm{t}-1}+\eta_{3} \ln \operatorname{Inst}_{\mathrm{t}-1}-+\eta_{4} \ln \operatorname{lit}_{\mathrm{t}-1}+\eta_{5} U p \operatorname{Spp}_{t-1}+\eta_{6} \ln G D P P C_{t-1}$

$+\sum_{\mathrm{t}=1}^{a} \psi_{3} \Delta(I M R)_{t-i}+\sum_{t=0}^{b} \mu 1 \Delta(\ln G h \exp )_{t-i}+\sum_{t=0}^{c} \gamma_{1} \Delta(\ln \operatorname{Inst})_{t-i}+\sum_{t=0}^{d} \Pi_{1} \Delta(\ln l i t)_{t-i}+$

$\sum_{t=0}^{e} \lambda \Delta(\text { Upop })_{t-1}+\sum_{T=0}^{f} \mu \Delta(\ln G D P P C) t_{-1}+\varepsilon_{3 t}$

Model 2

$\Delta(U 5 M R)_{t}=\beta_{0}+\eta_{1} U 5 M R \phi_{t-1}+\eta_{2} \ln \operatorname{lhexp}_{t-1}+\eta_{3} \ln \operatorname{Inst}_{-1-}+\eta_{4} \operatorname{lnlit}_{\mathrm{t}-1}+\eta_{5} U \operatorname{Uop}_{t-1}+\eta_{6} \ln$ GDPPC $_{t-1}$

$+\sum_{\mathrm{t}=1}^{a} \psi_{3} \Delta(U 5 M R)_{t-i}+\sum_{t=0}^{b} \mu 1 \Delta(\ln G h \exp )_{t-i}+\sum_{t=0}^{c} \gamma_{1} \Delta(\ln I n s t)_{t-i}+\sum_{t=0}^{d} \prod_{1} \Delta(\ln l i t)_{t-i}+$

$\sum_{t=0}^{e} \lambda \Delta(\text { Upop })_{t-1}+\sum_{T=0}^{f} \mu \Delta(\ln G D P P C) t-1+\varepsilon_{3 t}$

While the longrun relationship equations are stated as follows

For model I

$\Delta(\operatorname{Im} r)_{t}=\beta_{0}+\eta_{1} \operatorname{Im} r_{t-1}+\sum_{t=0}^{b} \mu_{L} L n G h \exp _{t-i}+\sum_{t=0}^{c} \gamma_{2}$ LnInst $_{t-i}+\sum_{t=0}^{d} \Pi_{4}$ Lnlit $_{t-i}+\sum_{t=0}^{e} \lambda_{5}$ Upop $_{t-1}+$

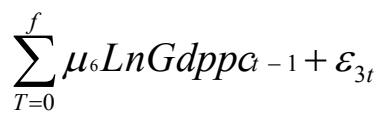

For model II

$\Delta(U 5 m r)_{t}=\beta_{0}+\eta_{1} U 5 m r_{t-1}+\sum_{t=0}^{b} \mu L n G h \exp _{t-i}+\sum_{t=0}^{c} \gamma_{2}$ LnInst $_{t-i}+\sum_{t=0}^{d} \Pi_{4}$ Lnlit $_{t-i}+\sum_{t=0}^{e} \lambda_{5}$ Upop $_{t-1}+$

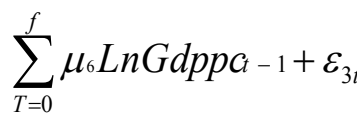

Where, $\Delta$ represents the first difference and $\varepsilon_{3 t}$ is a disturbance error term. The above equation indicates that health sector performance outcome is influenced by its past values. The null hypothesis that there is no co-integration relationship among the variables in the model, that is $\mathrm{H} 0:=\eta_{1}=\eta_{2}=\eta_{3}=\eta_{4}=\eta_{5}=\eta_{6}=\eta_{7}=0$ is tested against the alternative hypothesis i.e $\mathrm{H} 1=\eta_{1} \neq \eta_{2} \neq \eta_{3} \neq \eta_{4} \neq \eta_{5} \neq \eta_{6} \neq \eta_{7} \neq 0$ using Wald test (F-statistic). If the values of F-statistics are greater than the upper bound critical values, we reject the null hypothesis of no co-integration among the variables in the model. If the value of the F-statistic is lower than the lower bound critical value, we accept the null hypothesis of no cointegrating vector among the variables in the model. If the value of the F-statistic lies within the two critical values, the results will be inconclusive. 
Accordingly, the unrestricted error correction model (ECM) which follows the order of ARDL specification of growth equation of the above ARDL model in equation (5) and (6) is presented in Equation (9) and (10) for model I and model II respectively:

$$
\begin{aligned}
& \Delta(\operatorname{Im} r)_{t}=\beta_{0}+\sum_{t=1}^{a} \eta \Delta \operatorname{Im} r \phi_{t-1}+\sum_{\mathrm{t}=0}^{\mathrm{b}} \psi_{2} \Delta \operatorname{Lnghexp}_{\mathrm{t}-1}+\sum_{\mathrm{t}=0}^{\mathrm{c}} \gamma_{3} \Delta L n \operatorname{Inst}_{-1}-+\sum_{t=0}^{\mathrm{d}} \Pi_{4} \Delta \text { Lnlit }_{\mathrm{t} .}+ \\
& \sum_{t=0}^{e} \lambda_{s} \text { Upop }_{t-1}+\sum_{t=0}^{f} \mu_{6} \Delta \text { Lngdppc }+ \text { pect }_{t-1}+e_{t} \\
& \Delta(U 5 m r)_{t}=\beta_{0}+\sum_{t=1}^{a} \eta \Delta U 5 m r \phi_{t-1}+\sum_{\mathrm{t}=0}^{\mathrm{b}} \psi_{2} \Delta \text { Lnghexp }_{\mathrm{t}-1}+\sum_{\mathrm{t}=0}^{\mathrm{c}} \gamma_{3} \Delta \text { LnInst }_{\mathrm{t}-1}-+\sum_{t=0}^{\mathrm{d}} \Pi_{4} \Delta \text { Lnlit }_{\mathrm{t} .}+ \\
& \sum_{t=0}^{e} \lambda_{s} \text { Upop }_{t-1}+\sum_{t=0}^{f} \mu_{6} \Delta \text { Lngdppc }+ \text {,ect }_{t-1}+e_{t} .
\end{aligned}
$$

Where all the variables remained as defined with exception of ect that stands for error correction term and depicts the speed of adjustment in the model. its coefficients ( $\phi$ coefficients) are expected to have negative signs

The study also applied the ECM based Granger Causality test to trace the causal relationship among the variables included in the model. This was executed through a vector error correction model (VECM). The unrestricted error correction model that follows the order of the specification of equation 5 is presented in equation 11:

$$
\begin{aligned}
& \Delta(I M R)_{t}=\beta_{0}+\eta_{1} E C M \phi_{t-1}+\eta_{2} \operatorname{lnGhexp} \mathrm{t}_{-1}+\eta_{3} \ln \operatorname{Inst}_{\mathrm{t}-1-}+\eta_{4} \operatorname{lnlit}_{\mathrm{t}-1}+\eta_{5} \text { Upop }_{t-1}+\eta_{6} \ln \text { GDPPC }_{t-1} \\
& +\sum_{\mathrm{t}=1}^{a} \gamma_{1} \Delta(I M R)_{t-i}+\sum_{t=0}^{b} \gamma_{2} \Delta(\ln G h \exp )_{t-i}+\sum_{t=0}^{c} \gamma_{3} \Delta(\ln I n s t)_{t-i}+\sum_{t=0}^{d} \gamma_{4} \Delta(\ln l i t)_{t-i}+ \\
& \sum_{t=0}^{e} \gamma_{5} \Delta(\text { Upop })_{t-1}+\sum_{T=0}^{f} \gamma_{\Delta 6}(\ln G D P P C) t_{-1}+\varepsilon_{3 t}
\end{aligned}
$$

Employing the VECM framework, there are two sources of causation, i.e. from the ECM term and through the lagged dynamic terms. Consequently, we carried out three causality tests i.e. the short-run Granger non-causality test, the long-run causality (the weak exogeneity test) and the overall (the strong exogeneity test)

Testing for the long-run non-causality, the null hypothesis that the coefficient of $\mathrm{ECM}_{\mathrm{t}-1}$ is zero is tested in equation 3 against the alternative hypothesis $\mathrm{ECM}_{\mathrm{t}-1} \neq 0$, in order to determine whether the regressors granger cause IMR. Testing for short-run granger non-causality involves setting the coefficients of all orderlagged differences of the variables on the right-hand side equal to zero. The overall causality is conducted by jointly setting all the coefficients of the right-hand side variables including the coefficient of the error correction term equal to zero. All tests of causality will be conducted through the Wald test. The model was estimated using a maximum of 2 lags. The lag selection was based on the Akaike Information Criterion (AIC).

\section{1: Results and Discussion}

\section{Empirical Results}

The bound co-integration test approach to modeling relies on the assumption that the variables are stationary at levels or at first difference i.e. (1(0) or 1(1). This notwithstanding, the times series properties of the variable used in the model will still be examined to ensure that none of the variables is integrated of order two. Therefore, the times series properties of the variables used in the model were investigated using Augmented Dickey Fuller, and Philip Peron. The results of the ADF and the PP tests for the variables under investigation are presented in Table 2 
Public Healthcare Expenditure and Health Sector Performance in Nigeria: Implications .....

Table 2: Unit root test results

\begin{tabular}{|c|c|c|c|c|c|c|c|c|c|}
\hline \multicolumn{5}{|c|}{ Level } & \multicolumn{5}{|c|}{ Ist Difference } \\
\hline Variables & $\mathrm{PP}^{\dagger}$ & $\mathrm{ADF}^{\dagger}$ & $\mathrm{PP} \ddagger$ & ADF & $\mathrm{PP}^{\dagger}$ & $\mathrm{ADF}^{\dagger}$ & $\mathrm{PP} \ddagger$ & ADF & $\begin{array}{c}\text { Order of } \\
\text { Integration }\end{array}$ \\
\hline GDPPC & -0.4085 & -0.2477 & -0.7492 & -0.9444 & $-5.9599^{\circ}$ & -2.4941 & $-6.3205^{8}$ & $-4.6825^{8}$ & 1(1) \\
\hline LIT & 0.0155 & -0.6419 & $3.9797^{88}$ & $-3.8827^{88}$ & $-14.1526^{\circ}$ & $-7.5709^{8}$ & $-16.2726^{8}$ & $-7.4894^{\circ}$ & 1(1) \\
\hline INST & -1.2033 & -1.9267 & -1.4663 & -2.2141 & $-4.4263^{8}$ & $-4.3729^{\circ}$ & $-4.3664^{8}$ & $-4.3186^{8}$ & 1(1) \\
\hline GHEXP & 0.6461 & 0.6285 & $-4.3005^{*}$ & $-4.3644^{8}$ & $-15.1831^{*}$ & $-6.1350^{*}$ & $-18.5969^{\circ}$ & $-6.1793^{\circ}$ & 1(1) \\
\hline UPOP & -0.1812 & -0.7934 & $-3.2131^{888}$ & $-1.1641^{888}$ & $-4.1031^{8}$ & $-7.9522^{8}$ & $-4.0223^{88}$ & $-7.5947^{\circ}$ & 1(1) \\
\hline IMR & -0.7276 & .0 .5099 & -1.2661 & $-3.5919^{88}$ & $-7.1765^{8}$ & 2.0461 & $-7.5536^{8}$ & $-7.5384^{8}$ & 1(1) \\
\hline U5MR & -0.3982 & -0.1012 & -1.1693 & -1.0050 & $-6.8489^{\circ}$ & -1.9300 & $-7.0830^{8}$ & $-7.1626^{8}$ & 1(1) \\
\hline
\end{tabular}

$\mathrm{ADF} \uparrow$ and $\mathrm{PP} \uparrow=$ unit root tests with constant.

$\mathrm{ADF} \ddagger$ and $\mathrm{PP} \ddagger=$ unit root tests with constant and trend.

$*, * *$ and $* * *$ indicates statistical significance level at $1 \%, 5 \%$ and $10 \%$ respectively

Source: Author's Computation using E-view 7.1

From table (3) above, it has been confirmed that all the variables are integrated of order 1(1) going by the result of Augmented Dickey Fuller and Philip Peron. Employing ARDL bound test, we firstly applied OLS to Equation (5) and (6) for model I and II respectively, to test the existence of a cointegrating long run relationship based on the Wald test for the joint significance of the variables. This required the use of optimal lag thus, the optimal lag length for estimating the long term coefficients equation is selected using the Schwarz Bayesian criterion (AIC) To select the optimal lag length for the model, we fit an autoregressive model of order 3 (AR 3), generating the results of the Akaike information criterion (AIC) and the SBC.

However, the study utilizes the results of the AIC in the choice of optimal lag length for the estimated model. The results of the selection are presented in Table 3

Table 3: Lag selection results

\begin{tabular}{|c|c|c|c|c|c|c|c|c|c|c|}
\hline $\begin{array}{c}\text { Variable } \\
s\end{array}$ & \multicolumn{4}{|c|}{$\begin{array}{c}\text { AIC } \\
\text { lag length }\end{array}$} & \multicolumn{4}{|c|}{$\begin{array}{c}\text { SBC } \\
\text { lag length }\end{array}$} & \multicolumn{2}{|c|}{$\begin{array}{l}\text { Lag length } \\
\text { selected }\end{array}$} \\
\hline & 0 & $\overline{1}$ & 2 & 3 & 0 & 1 & 2 & 3 & $\begin{array}{c}\mathrm{AI} \\
\mathrm{C}\end{array}$ & $\begin{array}{l}\text { SB } \\
\text { C }\end{array}$ \\
\hline Gdppc & -2.5274 & $-4.6579^{8}$ & -4.6183 & -4.5682 & -2.4847 & $-4.5727^{8}$ & -4.4853 & -4.3976 & 1 & 1 \\
\hline Lit & 3.3662 & $0.7250^{8}$ & 0.7551 & 0.7906 & 3.4088 & $0.8103^{*}$ & 0.8831 & 0.9613 & 1 & 1 \\
\hline Inst & -2.5653 & -4.6627 & $-4.7502^{8}$ & .47092 & -2.5226 & -4.5774 & $-4.6223^{8}$ & -4.5385 & 2 & 2 \\
\hline Ghexp & 3.4472 & -0.8131 & -0.6535 & $0.6472^{8}$ & 3.4899 & 0.8984 & $0.7814^{8}$ & 0.8178 & 3 & 2 \\
\hline Upop & 1.4324 & -2.0986 & $-2.4018^{*}$ & -2.3624 & 1.4751 & -2.0133 & $-2.2822^{8}$ & -2.1918 & 2 & 2 \\
\hline Imr & 3.4557 & $1,0352^{8}$ & 1.0835 & 1.0704 & 3.4984 & $-1.1206^{\circ}$ & 1.1215 & 1.2409 & 1 & 1 \\
\hline U5mr & 0.4859 & $-2.2199^{\circ}$ & -2.1689 & -2.2083 & 0.5285 & $-2.1346^{\circ}$ & -2.0409 & -2.0376 & 1 & 1 \\
\hline
\end{tabular}

Notes: * Denotes minimum AIC and $S B C$.

As shown in table (3) for all the variables in the model the result of the test for optimal lag gives support to adoption of ARDL model of the order (1123211). Consequently, a co integration test was carried out using the bound test developed by Pesaran (2001), the result is shown in table 4(a) and 4(b) for model I and II respectively.

Table 4(a): Model I Bounds Test Results for Co integration

\begin{tabular}{|c|c|c|c|c|}
\hline & \multicolumn{5}{|c|}{ Computed Wald (F-statistic): 5.57* } \\
& \multicolumn{5}{|c|}{$\mathbf{0 . 0 5}$} & \multicolumn{2}{c|}{0.01} \\
\hline $\mathrm{K}=6$ & Lower Bound & Upper Bound & Lower Bound & Upper Bound \\
\hline Pesaran $\mathrm{F}^{*}$ & 2.45 & 3.61 & 3.15 & 4.45 \\
\hline Narayan $\left(\mathrm{F}^{*}\right)$ & 2.79 & 4.21 & 3.80 & 5.64 \\
\hline
\end{tabular}

Table 4(b): Model II Bounds Test Results for Co integration

\begin{tabular}{|c|c|c|c|c|}
\hline & \multicolumn{3}{|c|}{ Computed Wald (F-statistic): 5.91* } \\
\hline & \multicolumn{2}{|c|}{$\mathbf{0 . 0 5}$} & \multicolumn{2}{c|}{0.01} \\
\hline $\mathrm{K}=6$ & Lower Bound & Upper Bound & Lower Bound & Upper Bound \\
\hline Pesaran F* & 2.45 & 3.61 & 3.15 & 4.45 \\
\hline Narayan (F*) & 2.79 & 4.21 & 3.80 & 5.64 \\
\hline
\end{tabular}

Notes: $K$ is the number of regressors in the ARDL model. *, **, and *** denotes significance at $1 \%$, 5\% and $10 \%$ respectively. 


\section{Source: Authors' Computation using E-view 7.1}

Based on the principles underlying the ARDL approach to co-integration, the lower bound critical values assume that the explanatory variables are integrated of order zero, or I $(0)$, while the upper bound critical values assume that the explanatory variables are integrated of order one, or I(1). Hence, if the computed $F$ statistic is less than the lower bound value, the null hypothesis is not rejected. On the other hand, if the computed $F$-statistic is greater than the upper bound values the null hypothesis is rejected. However, if the computed $F$-statistic falls between the lower and upper bound values, the results are inconclusive.

Results in Table 4(a) and 4(b) suggest that the application of the bounds $F$-test using ARDL modeling approach indicate the existence of a long run relationship between IMR and Ghexp, INST, LIT, UPOP and GDPPC on one hand and U5MR and Ghexp, INST, LIT, UPOP and GDPPC on the other. The results show that the null hypothesis of no long run relationship is rejected at either $1 \%$ or $5 \%$ significance level. The Wald test ( $F$-statistic) of 5.57 and 5.91 for both model (I) and (II) respectively, are greater than the upper critical bound values of 4.45 and 5.64 for both Pesaran (2001) and Narayan (2004) respectively. Therefore, the null hypothesis of no co integration cannot be accepted at the $5 \%$ significance level and hence, there is a co-integration relationship between the variables in the model.

The confirmation of long run relationship among the variables in both models is followed by estimation of both long run and short run parameters of equation (5) and (6) through the application of ARDL model. The result is presented table 5 below

Table 5a: Long run estimates

\begin{tabular}{|c|c|c|c|c|c|c|}
\hline \multicolumn{7}{|c|}{ Long run estimates using ARDL based on AIC } \\
\hline \multicolumn{4}{|c|}{ Dependent variable: $\Delta($ IMR $)$} & \multicolumn{3}{|c|}{ Dependent variable: $\Delta(\mathrm{U} 5 \mathrm{mr})$} \\
\hline Variables & Coefficient & t-Statistics & Probability & Coefficient & t-Statistics & Probability \\
\hline Constant & 10.59185 & 3.010987 & 0.0052 & 2.1394 & 3.0207 & 0.0050 \\
\hline U5mr(-1) & & & & -3.3283 & -4.2562 & 0.0002 \\
\hline $\operatorname{Imr}(-1)$ & -0.660162 & -4.770254 & 0.0000 & & & \\
\hline Ghexp & -0.365853 & -2.077687 & 0.0464 & -0.0762 & -2.0791 & 0.0460 \\
\hline Inst & -5.581590 & -2.000443 & 0.0546 & -1.2922 & -2.3090 & 0.027 \\
\hline Lit(-1) & -0.166679 & -1.412544 & 0.1681 & -0.0269 & -1.1149 & 0.2734 \\
\hline Upop(-1) & & & & -0.3475 & -2.6211 & 0.0135 \\
\hline Upop & -1.181997 & -2.937992 & 0.0063 & & & \\
\hline Gdppc(-1) & -3.622188 & -2.755585 & 0.0099 & -0.6867 & -2.5108 & 0.0175 \\
\hline Inst(-1) & 9.735835 & 3.374739 & 0.0021 & 1.8388 & 3.1889 & 0.0033 \\
\hline Upopgr(-2) & 0.475053 & 1.346599 & 0.1882 & 0.2239 & 1.9475 & 0.0606 \\
\hline $\operatorname{Imr}(-2)$ & 0.319587 & 2.436077 & 0.0210 & & & \\
\hline \multicolumn{4}{|c|}{ 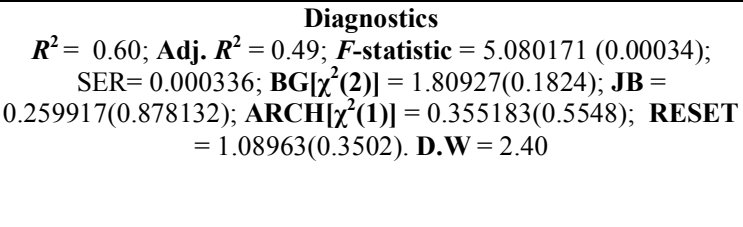 } & \multicolumn{3}{|c|}{$\begin{array}{c}\text { Diagnostics } \\
\boldsymbol{R}^{\mathbf{2}}=0.55 ; \mathbf{A d j .} \boldsymbol{R}^{\mathbf{2}}=0.43 ; \boldsymbol{F} \text {-statistic }= \\
4.673000(0.00080) ; \mathbf{S E R}=0.058479 ; \mathbf{B G}\left[\chi^{\mathbf{2}} \mathbf{( 2 )}\right]= \\
2.240243(0.1056) ; \\
\mathbf{J B}=1.235783(0.539080) ; \mathbf{A R C H}\left[\chi^{2}(\mathbf{1})\right]= \\
0.018107(0.8937) ; \mathbf{R E S E T}=0.022096(0.9825) \\
. \mathbf{D . W}=2.63\end{array}$} \\
\hline
\end{tabular}

$*$, ** and $* * *$ indicate statistically significant levels at $1 \%, 5 \%$ and $10 \%$

. SER: Standard error of regression.

ARCH: Engle's autoregressive conditional heteroskedasticity.

BG: Breusch-Godfrey LM test for serial correlation.

JB: Jarque-Bera test for normality of residuals.

RESET: Ramsey's regression equation specification error test.

Source: Authors' Computation using E-view 7.1

\section{2: Long run estimates}

Looking at table (5a) the estimated Long run equation result reveals that the entire coefficients are correctly signed, with the exception of INST at lag 1 and lagged value UPOP at lag 2 for both Model (I) and (II). There is a negative and statistically significant relationship between IMR in model (I) and U5MR in model (II) and its past value during the period of study, while at lag 2 IMR is positively and statistically to its past value. The coefficient of government healthcare expenditure is negatively signed and significant. This reveals that the higher the level of government commitment in healthcare sector the better the performance outcome of the sector. The result gives support to the earlier studies carried out by Anyawu et al. (2007). It should be noted that healthcare is widely recognized as a public good, its demand and supply cannot be left at the mercy of invisible hands or profit maximizing individual. Hence, the need for the government to play a major role in 
term of financial commitment in delivering good and qualitative healthcare services that is accessible and affordable.

The coefficient of the INST is also significant and correctly signed in both models. This implies that a $1 \%$ increase in the level of institutional quality will yield a decrease in infant mortality rate and under five mortality rate by $5.5816 \%$ and $1.2922 \%$ respectively in the long run. This is not surprising, because institutions are expected to facilitate adherence to rule of law, instill trust, moral and ethical value in health personnel, lower the cost and risk of doing business, correct government failure, and enhance strong sectors performance. Surprisingly, in both models the lagged value of INST show an increasing function of both IMR and U5MR indicating that a $1 \%$ change in the quality of institution in the country worsens the performance outcome of the health sector in the present study.

The coefficients of LIT, UPOP are all negatively and significantly related to heath sectors outcome. An increase in the rate of literacy results in fall in both IMR and U5MR rate. This is in line with our priori expectation, as parents get educated they become informed of new health practices and increase quest to live in a decent and diseases free environment. Also urbanization has significantly strong negative relationship with health sector, this may be due to the fact that larger percentage of urban population has access to better health facilities compare to rural dwellers, therefore the higher the population of urban dwellers the better the health sectors performance outcome in term of reduced infant and under five mortality. Interestingly, the lagged value of UPOP is positively related to IMR and U5MR in both models. This is not surprising in a country with poor institutions that encourage rent seeking behaviour and poor enforcement of rule of law that discourage long term planning with respect to urban planning and provision of social infrastructures to match population growth rate and government efficiency, increase urban population will result into urbanization and its associated problems that worsen health situations. This is in contrast with the study of Anyawu et al (2007) and Baldacci et al. (2004) that only confirmed a negative but insignificant relationship with health sectors performance.

The result of the income elasticity shows that as income of an individual increases his heath situation becomes improved. This is in line with economic theory that posits a positive elasticity between income and health goods. It is to be noted that in the long run an increase in level of income is assumed to be a reducing function of poverty and consequently improve living standard, demand for better health services that result into reduce infant and under-five mortality rate.

The diagnostic test statistics for the long run estimates are satisfactory. The adjusted $R^{2}$ for model (I) is $0.60 \%$, implying that $60 \%$ of variation in infant mortality rate is explained by lagged values of IMR $t-1$, GHEXP, INST, INST $t-1$, LIT $t-1$, UPOP, UPOP ${ }_{\mathrm{t}-1}$ and GDPPC $_{\mathrm{t}-1}$. While the adjusted $R^{2}$ for model (II) implies that $55 \%$ of variation in under- five mortality is explained by lagged value of U5MR , INST, INST $t-1$, LIT $t-1$, UPOP, $\mathrm{UPOP}_{\mathrm{t}-1}$ and $\mathrm{GDPPC}_{\mathrm{t}-1}$. Consequently, the coefficient of determination that measures the goodness-of-fit of the estimated model shows that both models have predictive capability as high as $50 \%$ and $43 \%$ for both model (I) and model (II) respectively. The $F$-statistic value of 5.080171 for model (I) and 4.673000 for model (II) are indicative of the overall statistical significance of both models at the $1 \%$ level as shown by the $p$-value. Thus, all the explanatory variables used in the model simultaneously explain the variations in the level of economic growth in Nigeria in Nigeria. The JB statistic 0.259917 for model (I) and 1.235783 for Model (II) and their associated $p$-value of 0.878132 and 0.539080 respectively indicate that the null hypothesis of normally distributed error term cannot be rejected. Not only that, the autoregressive conditional heteroskedasticity (ARCH) statistic and Breusch-Godfrey serial correlation LM test shows absence of heteroscedasticity and autocorrelation. Finally, the RESET statistic of both IMR and U5MR models are not statistically significant, implying the rejection of the null hypothesis of model misspecification as shown in table 5 panel A.

\section{2: Short Run Estimates:}

The result of the short run analysis of both model (I) and (II) are presented in table (5b) below.

Table 5b: Short run estimates

\begin{tabular}{|c|c|c|c|c|c|c|}
\hline \multicolumn{7}{|c|}{ Short run estimates using ARDL based on AIC } \\
\hline \multicolumn{4}{|c|}{ Dependent variable: $\Delta($ IMR) } & \multicolumn{3}{|c|}{ Dependent variable: $\Delta(\mathrm{U} 5 \mathrm{mr})$} \\
\hline Variables & Coefficient & t-Statistics & Probability & Coefficient & t-Statistics & Probability \\
\hline Constant & 0.028766 & 0.501913 & 0.6198 & -0.006052 & -0.457210 & 0.6508 \\
\hline$\Delta \mathbf{U} 5 \mathrm{mr}(-2)$ & & & & 0.136863 & 1.019064 & 0.3163 \\
\hline$\Delta \operatorname{Imr}(-3)$ & 0.384447 & 3.456170 & 0.0018 & & & \\
\hline$\Delta$ Ghexp & -0.453308 & -3.309224 & 0.0027 & -0.063204 & -2.107752 & 0.0435 \\
\hline$\Delta$ Inst & -1.388068 & -0.690062 & 0.4960 & -0.669565 & -1.492963 & 0.1459 \\
\hline$\Delta$ Lit(-1) & -0.440516 & -3.309224 & 0.0027 & -0.075321 & -2.406711 & 0.0225 \\
\hline$\Delta \mathbf{U p o p}(-1)$ & -1.393462 & -2.509765 & 0.0184 & -0.294515 & -2.256447 & 0.0315 \\
\hline$\Delta \operatorname{Gdppc(-1)}$ & 0.312076 & 0.160308 & 0.8738 & & & \\
\hline$\Delta$ Inst(-2) & 6.051106 & 3.014830 & 0.0055 & 1.389364 & 2.807972 & 0.0087 \\
\hline$\Delta$ Gdppc(1) & -6.179049 & -3.167474 & 0.0038 & & & \\
\hline$\Delta \operatorname{Gdppc(-2)}$ & & & & -0.560177 & -1.195717 & 0.2412 \\
\hline
\end{tabular}


Public Healthcare Expenditure and Health Sector Performance in Nigeria: Implications .....

\begin{tabular}{|c|c|c|c|c|c|c|}
\hline Ecm(-1) & -0.617207 & -4.640139 & 0.0001 & -0.438843 & -2.557625 & 0.0158 \\
\hline \multicolumn{4}{|c|}{$\begin{array}{l}\text { Diagnostics } \\
.60 ; \boldsymbol{F} \text {-statistic }=\mathbf{6 . 9 5 9 9 6 6}(0.00004) \\
(0.3503) ; \mathbf{J B}=2.093675(0.341046) ; \\
(0.3424) ; \mathbf{R E S E T}=1.016634(0.3187) \\
\text { D.W }=1.71\end{array}$} & \multicolumn{3}{|c|}{$\begin{array}{c}\text { Diagnostics } \\
\boldsymbol{R}^{2}=0.51 ; \text { Adj. } \boldsymbol{R}^{2}=0.37 ; \boldsymbol{F} \text {-statistic }=3.90555(0.0029) ; \mathbf{S E R} \\
=0.060450 ; \mathbf{B G}\left[\chi^{2}(\mathbf{2})\right]=0.293862(0.7476) ; \\
\mathbf{J B}=4.189801(0.123082) ; \mathbf{A R C H}\left[\chi^{2}(\mathbf{1})\right]=0.308978(0.7632) ; \\
\text { RESET }=0.9251523(0.3625) \\
. \mathbf{D . W}=1.85\end{array}$} \\
\hline
\end{tabular}

A Look at the table shows that in the short run IMR and U5MR are positively related to its lagged value although the impact remains insignificant in the case of U5MR model. Further, in our analysis the coefficient of GHEXP in both model (I) and (II) exhibits negative significant relationship at $1 \%$ and $5 \%$ respectively with the level of infant mortality rate as well as under-5 mortality rate. This further gives credence to our findings in the long run analysis.

The coefficients of INST are correctly signed in both models as thus in the long run although statistically insignificant in the short run. Good institution is thus a significant determinant of sustainable improve health sector performance in Nigeria. This implies that an improvement in the quality of institution in Nigeria will result into decrease in the rate of infant and under-5 mortality ceteris paribus. This further gives an empirical support to literature that has linked institutions to be germane for an improve health sector performance, that is sustainable, (Rajkumar and Swaroop,2008). Also as it is the case in the long run estimate, the coefficient of the lagged value of institutions has a negative and significant impact at $1 \%$ by both models on the health sector performance outcome in Nigeria. This is not surprising considering the level of institutional decay in the country. The explanation for this is that adaptation to newly introduced law by the public is not instantaneous. Hence, there is always a lag for any newly introduced rule of law or institutional reform to be effective. Hence and effective institutional reforms that is sustainable is hinged on sustainable implementation

LIT and UPOP (both at lag 1) are also both negative and significant at $5 \%$ for both model I and II. As for the coefficient of the GDPPC, in model I the result shows that in the short run increase income has a positive insignificant influence on the infant mortality rate, Indicating that a fall in the rate of infant mortality results into fall in per capita income. the reason behind this has been explained by Anyawu (2007) when he concludes that improvements in health technology and the associated reduction in child mortality reduces GDP per capita, at least temporarily (short run), if health innovations result in large increases in population. This appears to be the case in Nigeria, where population tend to be at increasing rate with growth rate of about $3 \%$ making it the most populous countries in Africa (see table 1). In relation to the under-5 mortality rate the coefficient of GDPPC corroborates the long run result, showing a significant negative relationship with U5MR, while in the case of LIT and UPOP the result also confirmed a significant negative relationship to both IMR and U5MR as reveals in the long run. All in line with economic theory and the same explanation applies as in the long run analysis

The ECM coefficient for both models are statistically significant and negatively signed, this further lend credence to the co-integration among the variables under investigation. The Error Correction Mechanism coefficient is about -0.617207 for model I and -0.438843 for model II. These suggest that about $62 \%$ and $44 \%$ of last year disequilibrium for both model I and model II respectively are corrected in the current year. Hence, when growth rate is above or below its equilibrium level, it adjusts by approximately $62 \%$ and $44 \%$ within the first year to ensure full convergence to their various equilibrium levels. The speed of adjustment is thus high for model I while a little bit slow for model II. Overall, both results indicate that in the short run, changes in institutional quality and government healthcare expenditure have significant impact on the rate of infant mortality and under -five mortality rate in Nigeria. Above all, both models pass through all the diagnostic test i.e. normality, misspecification, heteroskedasticity and auto correlation test.

\subsection{Stability of Government Healthcare expenditure and Health Sector Outcome}

In the final stage, the stability of the long-run coefficients is examined by using the CUSUM and CUSUM squares tests. The graphical presentations of these tests are presented in the figure below. To complement the CUSUM and CUSUMSQ test the Chow breakpoint test is also conducted, thus two tests of stability were carried out, the results of which do not reject the null hypothesis of stability. It can be concluded that the results are suggestive that the, Institutions, government healthcare expenditure and health performance outcome function for Nigeria is stable over the study period.

Carrying out the Chow test, a breakpoint (2000) was chosen. The reason for choosing this point is based on the facts that year 2000 mark the beginning of the era of government deliberate efforts in health institutional reforms through the introduction of National Health Insurance scheme (NHIS) in the country aim at encouraging out of pocket health service. The Chow $F$-statistic of 1.215872 for Model I and 0.986672 for model II are not statistically significant as indicated by their $p$-values of 0.3475 and 0.4791 respectively. It is concluded that the institutions, government healthcare expenditure and health performance outcome nexus in Nigeria has not undergone structural change over the period of 1970 to 2011. 
For the second test, to correct the disadvantage of the Chow test, which assumes knowledge of the exact breakpoint, the CUSUM and CUSUMSQ tests were applied to the residuals generated from Equation (9) and (10) respectively. The CUSUM and CUSUMSQ plots for both models do not cross the 5\% critical lines, implying that the stability of the institutions government healthcare expenditure and health performance outcome function exists over the entire sample period. The CUSUM and CUSUMSQ tests are shown in Figures (1) and (2) below.

Fig 1: Plots of CUSUM and CUSUMQ for Model I

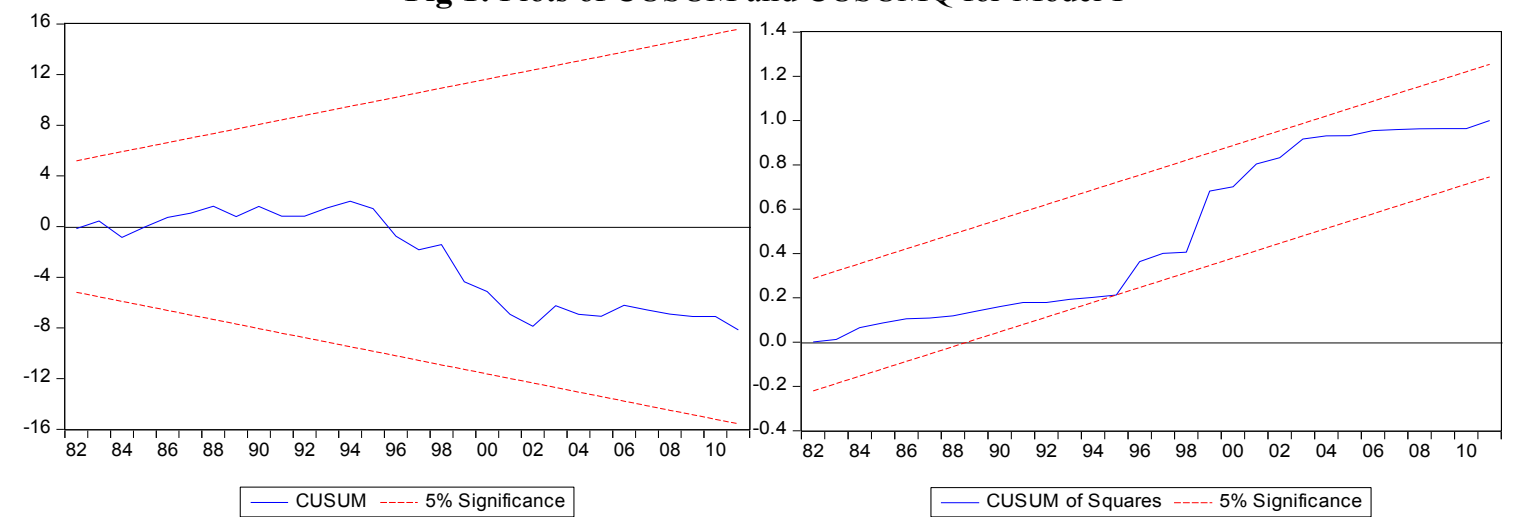

Fig 2: Plots of CUSUM and CUSUMQ for Model II
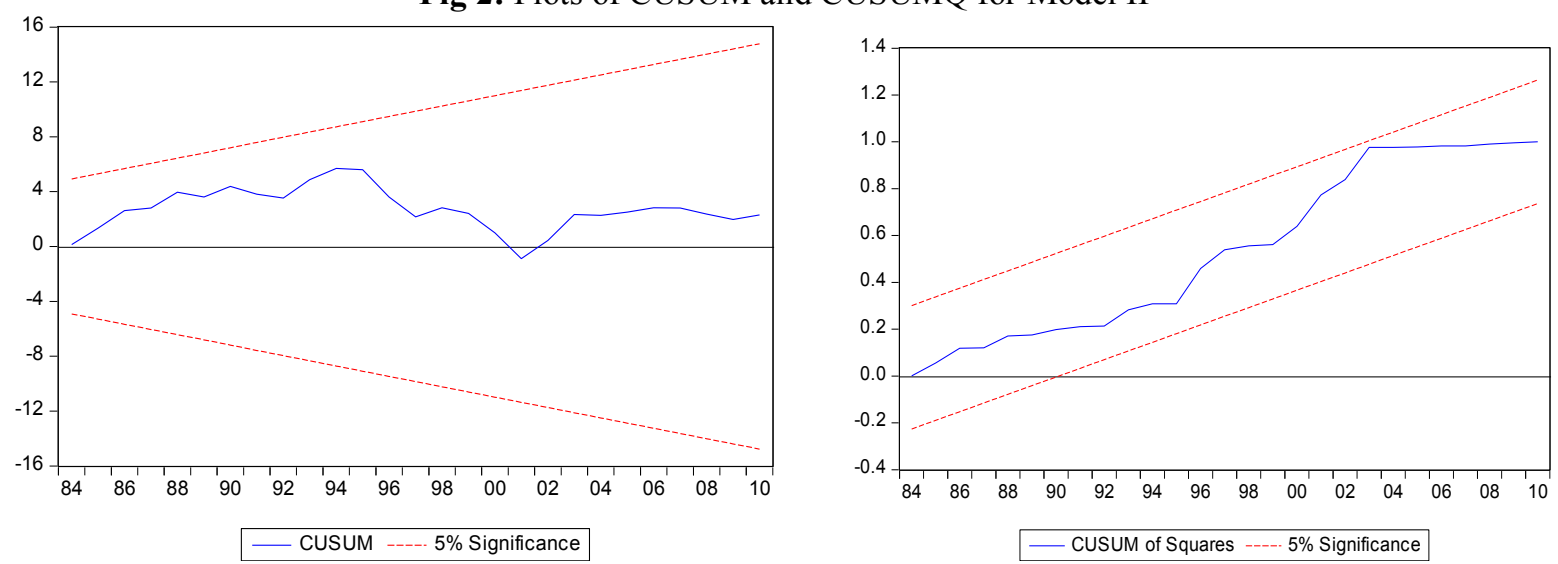

\section{4: Granger Causality Results}

Table (7) summarizes the causality estimates for the three tests specified in section 3

Table 7: Result of the VECM-Granger non-causality Test

\begin{tabular}{|c|c|c|c|}
\hline Hypothesis & Weak Exogeneity & Short Run Non- Causality & Strong Exogeneity \\
\hline Ho: $\Delta$ Ghexp $\rightarrow \Delta \mathrm{IMR}$ & $\beta \operatorname{Im} r \phi_{t-1}=0$ & $\Delta \mathrm{Ghexp}_{\mathrm{t}-1}=0$ & $\Delta \mathrm{Ghexp}_{\mathrm{t}-\mathrm{i}}=\beta \operatorname{Im} r \phi_{t-1}$ \\
\hline$\chi^{2}$ & $5.073842(1)^{* *}$ & $1.51987(1)$ & $5.087157(2)^{* * *}$ \\
\hline Ho: $\Delta \mathrm{Inst} \rightarrow \Delta \mathrm{OUTP}$ & $\beta \operatorname{Im} r \phi_{t-1}=0$ & $\Delta \mathrm{Inst}_{\mathrm{t}-\mathrm{i}}=0$ & $\Delta \mathrm{Inst}_{\mathrm{t}-\mathrm{i}}=\beta \operatorname{Im} r \phi_{t-1}$ \\
\hline$\chi^{2}$ & $5.073842(1)^{* *}$ & $0.355694(1)$ & $5.078944(2)^{* * *}$ \\
\hline Ho: $\Delta \mathrm{Lit} \rightarrow \Delta \mathrm{OUTP}$ & $\beta \operatorname{Im} r \phi_{t-1}=0$ & $\Delta \mathrm{Lit}_{\mathrm{t}-\mathrm{i}}=0$ & $\Delta \mathrm{Lit}_{\mathrm{t}-1}=\beta \operatorname{Im} r \phi_{t-1}$ \\
\hline$\chi^{2}$ & $5.073842(1)^{* *}$ & $0.64494(1)$ & $5.340770(2)^{* * *}$ \\
\hline Ho: $\Delta$ Upop $\rightarrow \Delta$ OUTP & $\beta \operatorname{Im} r \phi_{t-1}=0$ & $\Delta \mathrm{Upop}_{\mathrm{t}-\mathrm{i}}=0$ & $\Delta \mathrm{Upop}_{\mathrm{t}-\mathrm{i}}=\beta \operatorname{Im} r \phi_{t-1}$ \\
\hline$\chi^{2}$ & $5.073842(1)^{* *}$ & $3.640715(1)^{* * *}$ & $5.250449(2)$ \\
\hline$\chi^{2}: \Delta \mathrm{Gdppc} \rightarrow \Delta \mathrm{OUTP}$ & $\beta \operatorname{Im} r \phi_{t-1}=0$ & $\Delta \mathrm{Gdppc}_{\mathrm{t}-\mathrm{i}}=0$ & $\Delta \mathrm{AGdppc}_{\mathrm{t}-\mathrm{i}}=\beta \operatorname{Im} r \phi_{t-1}$ \\
\hline
\end{tabular}

$*$, **, and ** denote statistical significance at 1\%, 5\% and $10 \%$ levels respectively. Figures in parenthesis indicates the degree of freedom 


\section{Source: Authors' Computations using E-view7.1}

The results of the short-run non-causality in Table 7 show that with the exemption of UPOP (representing urban population size) that is statistically significant at the $10 \%$ levels, all other variables i.e. Gexp (representing government healthcare expenditure), institutions (INST), LIT (representing literacy rate)and GDPPC(representing growth in income) do not Granger cause IMR (Infant mortality rate). For the long-run non-causality, the null hypothesis that IMR does not Granger-cause other variables in the system is rejected and is statistically significant at the $5 \%$ level.

The overall causality in the system (the strong exogeneity) indicates that the null hypothesis that institutions and government healthcare expenditure does not granger cause infant mortality rate is rejected at $10 \%$ level of significance. In addition, the results indicate that GDPPC and LIT do Granger-cause infant mortality and that they are statistically significant at $10 \%$ level.

\section{Conclusion and Policy Recommendations}

The purpose of this study was to test for both short run and long run relationship as well as Granger causality between government healthcare expenditure, institutions and health sector performance outcome in Nigeria using ARDL approach to VECM-Granger non-causality tests.

Empirical findings suggest that a long run relationship between, government health expenditure, institutions and infant mortality rate on one hand and between under -five mortality rate, government health expenditure and institutions on the other exist in Nigeria. The long run and short run estimated elasticity coefficient of government healthcare expenditure and institutions are negatively, implying essentiality of government financial commitment and institutions in the path to achievement of better health outcome. Although the lagged value of institutions has a positive impact on the proxy for health sector performance indicating the effects of institutional decay in an economy that lack qualitative institutions like Nigeria.

Also the estimated coefficients of LIT, GDPPC, and UPOP are all negatively significant both in the short run and in long run with the exception of GDPPC that was positively insignificant in the short - run. The lagged value of urban population (at lag 2) reveals a positive relationship with both IMR and U5MR in the long run. The overall causality test suggests that the null hypothesis that IMR does not Granger-cause other variables in the system is rejected and is statistically significant at the 5\% level. This is further supported by the confirmation of the existence of co-integration among the variables in the model. The strong exogeneity tests indicate that institutions, government healthcare expenditure, urban population, literacy and growth in income Granger-cause infant mortality rate at $10 \%$ significance level.

From the forgoing, one can conclude that government involvements in term of funding and provision of an enabling institutions is germane to better health outcome in a developing economy like Nigeria. It should be noted that health has been categorized as public good, which cannot be left at the mercy of invisible hand. Government spending and urbanization do have positive impacts on health outcome if only there exists a qualitative institution that provides an enabling environment. An increasing urban population that is accompanies with proper urban planning and respect for rule of law through qualitative institutions will certainly result into economic development, the absence of which will result into deteriorating health status of the citizens and poor human capital development. This is suggested from the result of our empirical findings both in the long run and short run analysis. Apart from the above, suggestive of the implication of our analysis on economic development is the bidirectional causality that exists between IMR to growth income. This is not surprising since a healthy human capital remains to be pre facie to development by reducing dependency ratio, increase output, and consequently decreasing rate of poverty in an economy.

Drawing from the foregoing, the followings are recommended. Government investment on health and education should be sustained rather than been left at the mercy of market due to its roles in human capital development necessary for development. This should be corroborated with adoption of policies that can ensure total overhauling of our institutions capable of driving investment in heath infrastructures, ensuring sustainable urban planning as well as reorientation of the individuals in term of altitudes, trust, respect for rule of law and accountability, thereby embedded in our human capital ethical value required of a health worker. Not only that the positive impact of the ongoing out of pocket health policies in the country like National Health Insurance Scheme, primary healthcare services among others on health status may become unsustainable without good institutions, but as well makes the achievement of the millennium development goal objectives by 2015 elusive. 


\section{References}

[1]. AFDB (2011) “Africa Economic Outlook 2011” African Development Bank Annual Report.

[2]. Agenor, P.R (2007): "Health and Infrastructure in a model of Endogenous Growth" Journal of Macroeconomics Vol. 28, pp.768774.

[3]. Ajayi, S. I. (2002): "INSTITUTIONS: The Missing Link in the Growth Process"? Being a published presidential Address delivered at the $43^{\text {rd }}$ Annual Conference of NES, Lagos, 7-8, August.

[4]. Ajayi, S. I. (2002): "INSTITUTIONS: The Missing Link in the Growth Process"? Being a published presidential Address delivered at the $43^{\text {rd }}$ Annual Conference of NES, Lagos, 7-8, August

[5]. Anand, Sudhir and Martin Ravallion. (1993) "Human development in poor countries: On the role of private incomes and public services.” Journal of Economic Perspectives 7(1):133-150

[6]. Andrew Cassels (1995) “Health Sector Reform: Key Issues in Less Developed Countries” Journal of International Development Vol. 1 No. 3, pp.329 -347.

[7]. Anyanwu J.C. and Andrew E. O. E. (2007) "Health Expenditures and Health Outcom Africa" African Development Bank Economic Research Working Paper No 91 (December 2007)

[8]. Arah O. A. Klazinga N. S., Delnoij D. M. J., Ten Asbroek A. H. A. And Custers T. (2003)“Conceptual frameworks for health systems Performance: A Quest for Effectiveness, Quality and Improvement” International Journal for Quality in Health, Volume 15, Number 5: pp. 377-398

[9]. Asekunowo V. O. (2010) "Funded contributory Pension Scheme, Financial Deepening and Economic Growth: What Does the Evidence Say So Far about the Nigeria Economy?” CBN Bullion Vol.34, No 1. pp 35-46. Jan. - Mar., 2010

[10]. Ataguba J. E.O, Akazili J. (2010) "Healthcare financing in South Africa: moving towards universal coverage" Continue Medical Education Vol 28, No 2. pp.74 -78

[11]. Bakare A.S and Olubokun Sanmi (2011) "Healthcare Expenditure and Economic Growth in Nigeria: An Empirical Study" Journal of Emerging Trends in Economics and Management Sciences (JETEMS) Vol. 2 No.2. Pp. 83-87.

[12]. Baldacci, E. et al. (2004), "Social Spending, Human Capital, and Growth in Developing Countries: Implications for Achieving the MDGs", IMF Working Paper, no. wp/04/217, Washington DC

[13]. Better Results in Education and Healthcare?”, IMF, Washington D.C, Working paper 99/21.

[14]. Bidani, Benu and Martin Ravallion. (1997) "Decomposing social indicators using distributional data.” Journal of Econometrics Vol. 77(1999), pp.125-139.

[15]. Bingjie Hu and Ronald U. M. (2010) "Public Spending, Governance and Child Health Outcomes: Revisiting the Links" Unedited Discussion Draft Unicef Policy And Practice

[16]. Chaabouni, S., and Abednnadher, C. (2010). "The determinants of health expenditures in Tunisia: An ARDL bounds testing approach". Available on the internet at http://www.unicaen.fr/recherche/mrsh/files/B7_3_Chaabouni_ABEDNNADHER_def.pdf\&sa=U\&ei=v0v2UY7BNvH07Aas7YGQ Aw\&ved=0CBoQFjAA\&usg=AFQjCNGx5is___-_ijxR35YJLZZkRhEPlvBfQ.

[17]. Clague C. Keefer P, Knack S, and Olson M..(1999) "Contract Intensive Money : Contract Enforcement, Property Rights and Economic Performance”, Journal of Economic Growth Vol. 4,June pp.185-211.

[18]. Filmer, D. and Pritchett L. (1997) “Child Mortality and Public Spending on Health: How Much Does Money Matter?”, World Bank Policy Research Working Paper No. 1864 (Washington: World Bank).

[19]. Filmer, Deon and Lant Pritchett. (1999) "The impact of public spending on health: Does money matter?" Social Science and Medicine Vol. 49, pp.1309-1323.

[20]. Garba, P. K. (2012): "The Impossibility of Sound Economic Outcomes with a sound Management and Leadership": Being Inaugural Lecture (2011/2012), University of Ibadan.

[21]. Greiner, A. (2005):"Fiscal policy in an Endogenous Growth Model with Public capital and pollution” Japanese Economic Review. Vol. 56, 67-84

[22]. Gupta S, Verhoeven M and Tiongson E. (1999), "Does Higher Government Spending Buy

[23]. Gupta S, Verhoeven M. and Tiongson E. (1999), "Does Higher Government Spending Buy Better Results in Education and Healthcare?", IMF, Washington D.C, Working paper 99/21.

[24]. Gupta S, Verhoeven, M and Tiogson E (2001), "Public Spending on Healthcare and the Poor", IMF Working Paper, Fiscal Affairs Department

[25]. Gupta, Sanjeev, Hamid Davoodi and Erwin Tiongson. (2002). "Corruption and the provision of healthcare and education services." In George Abed and Sanjeev Gupta, Eds., Governance, Corruption and Economic Performance. Washington, D.C.: IMF.

[26]. Hanmer, L., Lensink R. and White H. (2003). "Infant and Child Mortality in Developing Countries: Analysing the Data for Robust Determinants." Journal of Development Studies, Vol.40, No.1, pp. 101-108.

[27]. Imoughele, L. E. and Ismaila, M. (2013) "Determinants of Public Healthcare Expenditure in Nigeria: An Error Correction Mechanism Approach" International Journal of Business and Social Science Vol. 4 No. 13; spp. 220-233

[28]. Kaufman, D., Kraay, A., \& Mastruzzi, M., (2004) "Governance matters III: governance indicators for 1996, 1998, 2000, and 2002." World Bank Economic Review, 18, 253-287, 2004.

[29]. Kaufmann D., Kraay A,. and Mastruzzi M. (2013). “The Worldwide Governance Indicators, 2013 Update” www.govindicators.org

[30]. Kaufmann Daniel, Aart Kraay and Massimo Mastruzzi (2013). "The Worldwide Governance Indicators, 2013 Update" www.govindicators.org

[31]. Kaufmann, D. and S.-J. Wei. (1999) “Does “Grease Money” Speed Up the Wheels of Commerce?” NBER Working Papers 7093. National Bureau of Economic Research, Inc.

[32]. Kim, K., and Moody, P.M. (1992), "More Resources, Better Health? A Cross-National Perspective," Social Science and Medicine, Vol. 34, pp. 837-42.

[33]. Maureen Lewis (2006) "Governance and Corruption in Public Healthcare Systems" Center for Global Development Working Paper Number 78 January 2006

[34]. Mordi N.O C, Abwaku E, Banji S. A (2010),"The Changing Structure of the Nigerian Economy" Published by Research Department, CBN, 2010 Pp. 297.

[35]. Musgrove, P (1996), "Public and Private Roles in Health," Technical Report 339, World Bank Washington, D.C.

[36]. Narayan P.K. (2004) "Reformulating Critical Values for the Bound F-Statistics Approach to Co-integration: An Application to the Tourism Demand Model for Fiji”. Discussion Paper No. 02/04, Department of Economics, Monash University, Victoria 3800

[37]. North, D. C. (1991): Institutions, The Journal of Economic Perspectives vol.5 No.1, pp.97-112

[38]. Odusola, A.E. (1998) "Rekindling Investment and Economic Development in Nigeria". NES Selected Papers for the 1998 Annual Conference. 1998. 
[39]. Olaniyan, O., Onisanwa, I.D and Oyinlola, A (2013). "Healthcare Expenditures and GDP in Sub-Saharan African Countries: Evidence from Panel Data". Paper submitted for presentation at the 2013 Centre for the Study of African Economies Conference on Economic Development in Africa to be held at St Catherine's College, Oxford, 17-19 March 2013

[40]. Olayinka A. L. and Olanrewaju O. (2013) "Health Expenditure and Health Status in Northern and Southern Nigeria: A Comparative Analysis Using National Health Account Framework" African Journal of Health Economics AJHE-2013-0003 pp. 1-15

Patricio M,. Edward F. Rifat A. and Sevil K. Salakhutdinova (2008) "Public Spending in Russia for Healthcare: Issues and Options" Europe and Central Asia Region (ECA), , Russia Country Management Unit, The World Bank.

[42]. Pesaran M.H and Shin Y. (1999)"An Autoregressive Distributed Lag Modelling approach to Co-integration Analysis" In Storm S. Ed., Econometric and Economic Theory in $20^{\text {th }}$ Century. The Ragner Frisch Contennial Symposium. Cambridge University Press, Chapter 11.

[43]. Pesaran M.H, Shin Y. And Smith R.(2001) "Bounds Testing Approaches to the Analysis of Level Relationships", Journal of Applied Econometrics Vol.16, Pp.289-326.

[44]. Rajkumar, Andrew Sunil and Vinaya Swaroop. (2008). "Public spending and outcomes: Does governance matter?" Journal of Development Economics Vol. 86, pp.96-111.

[45]. Riman Hodo Bassey (2012) "Healthcare Financing and Health outcomes in Nigeria: A State Level Study using Multivariate Analysis" International Journal of Humanities and Social Science vol. 2., No 15 Pp.296-305

[46]. Schultz, T. Paul (1993), "Mortality Decline in the Low-Income World: Causes and Consequences," Economic Growth Center Discussion Paper No. 681 (New Haven: Yale University)

[47]. UNDP (2013) "List of Countries by Human Development Index" United Nation Development Project Download from the Web http://en.wikipedia.org/wiki/List_of_countries_by_Human_Development_Index

[48]. UNECA (2012): "Economic Transformation for Africa's Development", United Nations, Economic Commission for Africa, Macroeconomic policy Division, C-10 Meeting April. Washington D, C.

[49]. University Press: New York, NY.

[50]. World Bank. (1993), World Development Report 1993: Investing in Health. Oxford University Press: New York, NY. World Bank. (1993), World Development Report 1993: Investing in Health. Oxford

[51]. Yaqub, J., Ojapinwa T.V. Yussuff R.O (2010) "Public Health Expenditure and Health Outcome In Nigeria: The Impact Of Governance” European Scientific Journal vol. 8, No.13 PP.189 -201 eujournal.org/index.php/esj/article/viewFile/206/248 